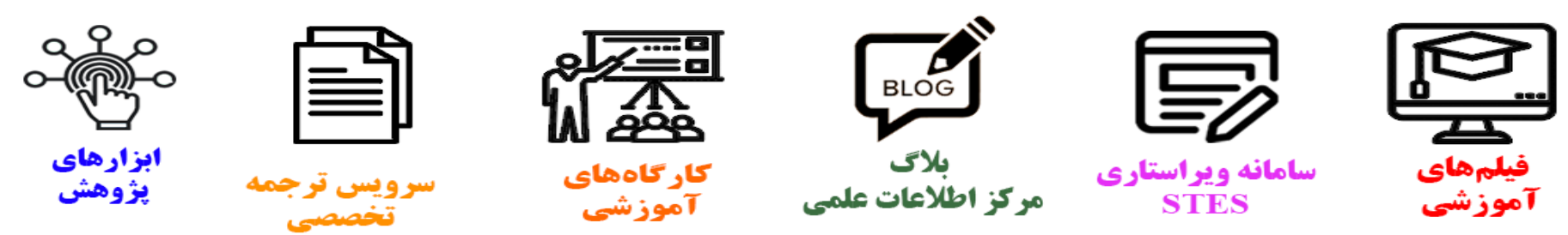

\title{
(c)
}

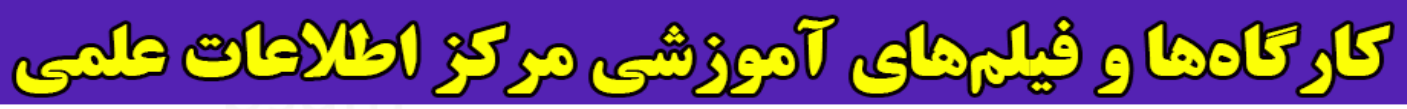
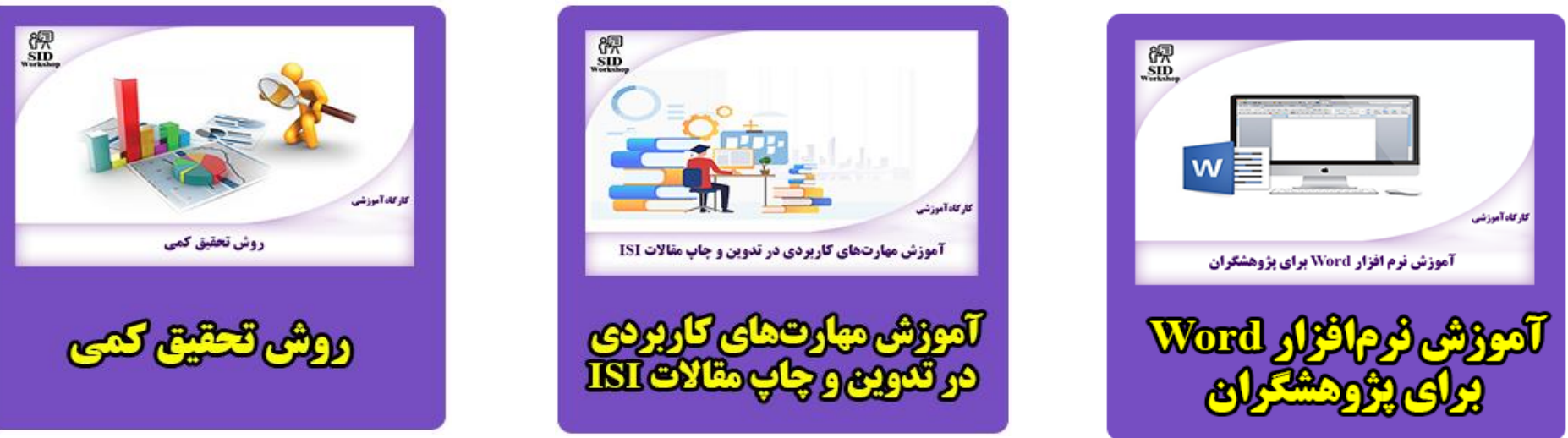


\title{
International Journal of Engineering
}

Journal Homepage: w w w. ije.ir

\section{Prediction of Deformation of Circular Plates Subjected to Impulsive Loading Using GMDH-type Neural Network}

\author{
H. Babaei * \\ Department of Mechanical Engineering, Engineering Faculty, University of Guilan, Rasht, Iran
}

\section{PAPER I NFO}

Paper history:

Received 11 August 2013

Received in revised form 31 May 2014

Accepted 26 June 2014

\section{Keywords:}

Neural Network

Modelling, Circular Plate

Impulsive Load

Deformation

\section{$A B S T R A C T$}

In this paper, experimental responses of the clamped mild steel, copper, and aluminium circular plates are presented subjected to blast loading. The GMDH-type (Group Method of Data Handling) neural networks are then used for the modelling of the mid-point deflection thickness ratio of the circular plates using those experimental results. The aim of such modelling is to show how the mid-point deflection varies with the variations of the important parameters. Further, it is shown that the use of dimensionless input variables, rather than the actual physical parameters, in such GMDH-type network modelling leads to simpler polynomial expressions which can be used for modelling and prediction purposes. It is also demonstrated that Singular Value Decomposition (SVD) can be effectively used to find the vector of coefficients of quadratic sub-expressions embodied in such GMDH-type networks. Such application of SVD will highly improve the performance of GMDH-type networks to model the nonlinear dynamic behavior of circular plates.

\section{INTRODUCTION}

Solid phase-based forming has attracted a great amount of interest as a new technology of forming since it can compensate the disadvantages of the conventional forming processes. However, it still has difficulties in industrial production due to problems such as the reheating of the billet, high manufacturing costs, and an inability to produce large parts[1]. High rate metal forming processes are fairly well developed. These techniques have some advantages over conventional metal forming. These include the ability to use singlesided dies, reduced spring back, and improved formability[2].

One of the structural problems widely analyzed has been that of a metallic circular plate fully clamped around its outer boundary subjected to transverse impulsive loads [3].

Studies of the behavior of plates subjected to impulsive loading have been carried out by Nurick and Martin [4, 5]. They presented an overview of the theoretical and experimental results that dealt mostly

\footnotetext{
*Corresponding Author's Email: ghbabaei@guilan.ac.ir (H. Babaei)
}

with a plate that was loaded uniformly over the plate area. Experimental works on structural components subjected to blast loading were performed in order to study permanent large inelastic deformation (mode I) to investigate both tensile tearing (mode II ) and transverse shear rupture (mode III) at the supports [6].

A technique that is generally adopted for sheet metal forming operations using impulsive loading that involves very large sheets and usually axi-symmetric can be found in the literature[6-8]. The method is essentially dynamic and the forming is induced by exposing sheet metal surface to an incoming pressure wave generated by explosion. However, the direct application of the pressure wave on the metal surface gives rise to a stress-strain field distribution of unacceptable profile, which may lead to premature failure of material. Hence, to improve the formability limit an alternative technique referred as "plug cushion forming" has been introduced. A plug of soft material is inserted in contact with plate between the source of explosion and the plate. Thus, the pressure wave instead of reaching the plate directly exerts itself on the plate via the plug. Depending on the thickness of plate and plug, the deformation process is slowed down, since the 
plug acts as a conduit to transfer the energy at a relatively slower rate to the plate [9]. There have been many research efforts for theoretical modelling of the dynamic response and deformation of thin plates to predict the relationship of deflection-thickness ratio as a function of the amount of impulse, plate geometry, plate dimension, and plate material [10].

Modelling of processes and system identification using input-output data have always attracted many research efforts. In fact, system identification techniques are applied in many fields in order to model and predict the behaviours of unknown and/or very complex systems based on given input-output data [11]. Theoretically, in order to model a system, it is required to understand the explicit mathematical input-output relationship precisely. Such explicit mathematical modelling is, however, very difficult and is not readily tractable in poorly understood systems. Alternatively, soft computing methods [12, 13], which concern computation in imprecise environment, have gained significant attention. The main components of soft computing, namely, fuzzy-logic, neural network, and genetic algorithm have shown great ability in solving complex non-linear system identification and control problems. Several research efforts have been expended to use evolutionary methods as effective tools for system identification [12-14]. Among these methodologies, the Group Method of Data Handling (GMDH) algorithm is self-organizing approach by which gradually more complicated models are generated based on the evaluation of their performances on a set of multi input- single-output data pairs $(X i, y i)(i=1,2$, ..., $M)$. The GMDH was firstly developed by Ivakhnenko [15] as a multivariate analysis method for complex systems modelling and identification. In this way, GMDH was used to circumvent the difficulty of having a priori knowledge of a mathematical model of the process being considered. The main idea of GMDH is to build an analytical function in a feed-forward network based on a quadratic node transfer function [14, 16] whose coefficients are obtained using a regression technique. GMDH, which is an inductive learning method, is similar to neural approach but is bounded in nature. In neural networks, the output of each unit passes through a threshold logic unit which can be linear or nonlinear transfer function such as sigmoid functions. Each unit depends on the state of many other units which creates different level of interactions in such unbounded network structure [16]. The error of output is back-propagated in order to re-tune the connection weights adaptively. However, in inductive GMDH algorithms, a bounded network structure with all combinations of input pairs is trained by scanning the measure of threshold objective function through the optimal connection weights for all inputs-output data pairs [17-19].

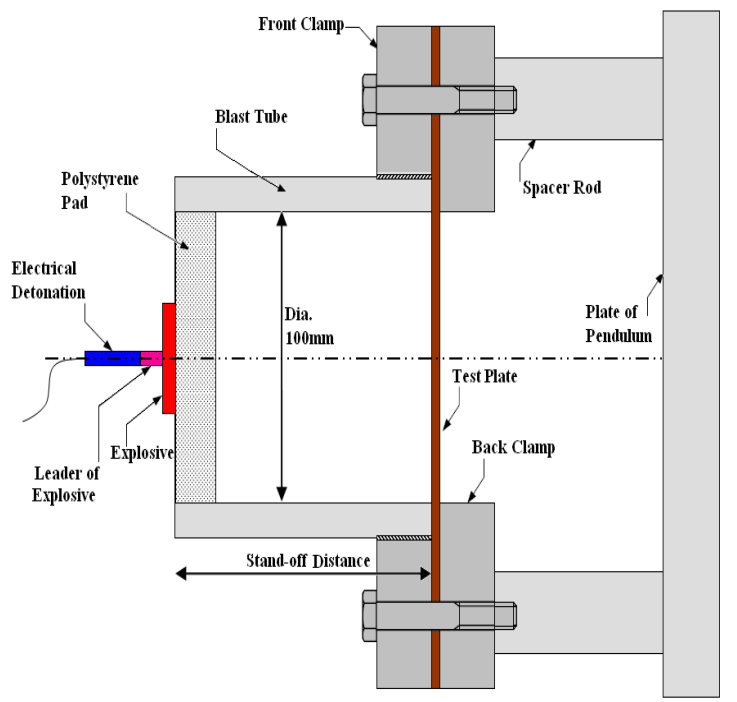

Figure 1. Schematic representationof the experimental test rig

In recent years, the use of such self-organizing network has lead to successful application of the GMDH type algorithm in a broad range area in engineering, science, and economics [18, 20-22]. In this paper, it is shown that GMDH-type neural network can effectively model and predict the deflection of circular plate subjected toblast loading. In this way, a method for designing such network is proposed and its performance is enhanced using Singular Value Decomposition (SVD). In this paper, experimental data are used to find an equation for predicting deflectionthickness ratio using GMDH-type neural network and SVD method. In this way, input variables are regrouped as dimensionless parameters which are then used to obtain the equation of deflection-thickness ratio of circular clamped plates under impulsive loading.

\section{EXPERIMENTAL TESTS}

Test specimens were prepared from commercially pure (99.5\%) copper, aluminium alloy 1200-H4 and mild steel. The specimens were $200 \mathrm{~mm}$ by $200 \mathrm{~mm}$ and varied in thickness from $1.6 \mathrm{~mm}$ to $3.0 \mathrm{~mm}$. Plate specimens were clamped in a frame, comprising of two $(200 \mathrm{~mm} \times 200 \mathrm{~mm})$ frames made from $20 \mathrm{~mm}$ thick mild steel plating. Two stand-off distances were employed to vary the spatial uniformity of the loading $-50 \mathrm{~mm}$ and $300 \mathrm{~mm}$. A tube of required length was screwed into the front clamp; the back frame had a $100 \mathrm{~mm}$ diameter hole (same as the internal tube diameter). Each specimen had a circular exposed area with a diameter of $100 \mathrm{~mm}$. Plastic explosive (PE4) was moulded into the appropriate charge diameter disc and sited at the open end of the blast tube, as shown in Figure 1. 
TABLE 1. Summary of tensile test results on steel, copper and aluminium

\begin{tabular}{lccc}
\hline Material & $\begin{array}{c}\rho \\
\text { Density }\left(\mathbf{k g} / \mathbf{m}^{\mathbf{3}}\right)\end{array}$ & $\begin{array}{c}\text { Nominal } \\
\text { thickness (mm) }\end{array}$ & $\begin{array}{c}\text { Yield } \\
\text { stress(MPa) }\end{array}$ \\
\hline Steel & 7800 & $1.6,2.0,3.0$ & 318 \\
Copper & 8940 & 2.0 & 277 \\
& & 3.0 & 201 \\
$\begin{array}{l}\text { Aluminium } \\
\text { Alloy 1200 }\end{array}$ & 2700 & $2.0,3.0$ & 120 \\
H4 & & & \\
\hline
\end{tabular}

The blast loading was generated by electrical detonation of the explosive charge allowing the resulting blast wave to travel down the blast tube and impinge upon the target plate. Tensile test specimens were prepared from commercially pure $(99.5 \%)$ copper, aluminium alloy 1200-H4 and mild steel with different thicknesses. The mean average values of yield stress and ultimate tensile stress are calculated for each material for different thicknesses. A summary of the properties of different plate materials is given in Table 1. More details of experimental procedure has been reported in the literature [23].

\section{EXPERIMENTAL RESULTS}

Photographs of deformed plate of the plates tested at 50 , $300 \mathrm{~mm}$ stand-off distance are given in Figure 2. The experimental results obtained from large number of tests are presented in Table 2. The charge masses listed include the 1.g leader charge attached to detonator, for example 9.g equals to $(8+1) \mathrm{g}$. For the first set of test, the stand-off distance was held constant at $50 \mathrm{~mm}$ and $300 \mathrm{~mm}$. For each material (steel, copper and aluminium) with three different thicknesses, the effect of impulse values was investigated.

\section{MODELLING USING GMDH-TYPE NEURAL NETWORKS}

The classical GMDH algorithm can be represented as a set of neurons in which different pairs of neurons in each layer are connected through a quadratic polynomial and thus produce new neurons in the next layer. Such representation can be used in modelling to map inputs to outputs. The formal definition of the identification problem is to find a function $\hat{f}$ which can be approximately used instead of actual one, $f$, in order to predict output $\hat{y}$ for a given input vector
$X=\left(x_{1}, x_{2}, X_{3}, \ldots, x_{n}\right)$ as close as possible to its actual output $y$.Therefore, given $M$ observation of multiinput-single-output data pairs so that:

$y_{i}=f\left(x_{i 1}, x_{i 2}, x_{i 3}, \ldots, x_{i n}\right)(i=1,2, \ldots, M)$,

it is now possible to train a GMDH-type neural network to predict the output values $\hat{y}_{i}$ for any given input vector $X=\left(X_{i 1}, x_{i 2}, X_{i 3}, \ldots, X_{i n}\right)$, that is:

$\hat{y}_{i}=\hat{f}\left(x_{i 1}, x_{i 2}, x_{i 3}, \ldots, x_{i n}\right)(i=1,2, \ldots, M)$.

The problem is now to determine a GMDH-type neural network so that the square of difference between the actual output and the predicted one is minimised, that is:
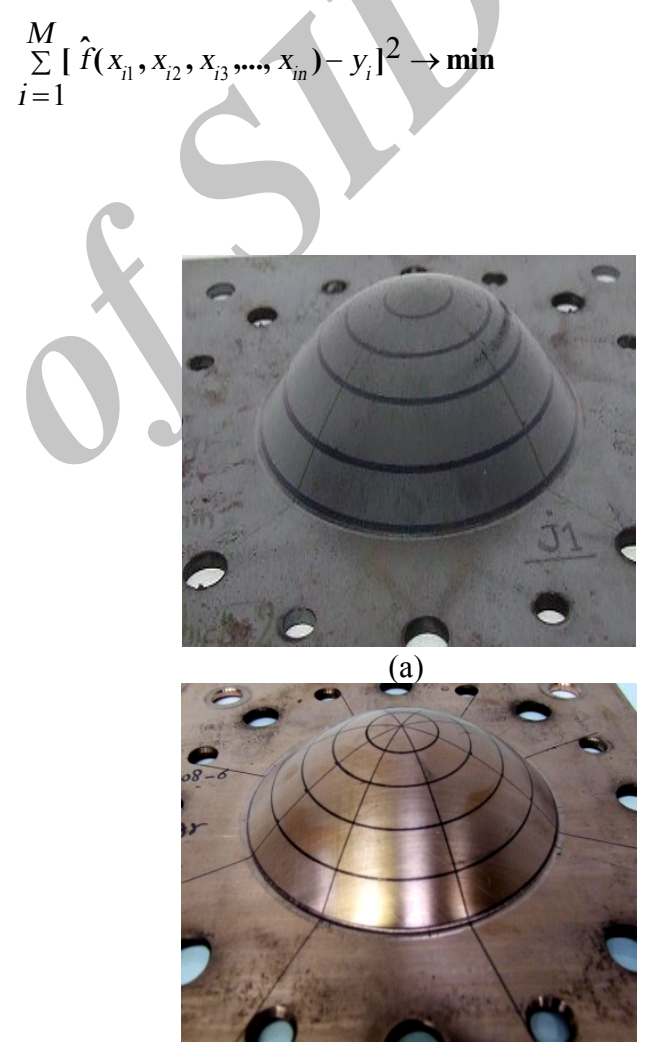

(b)

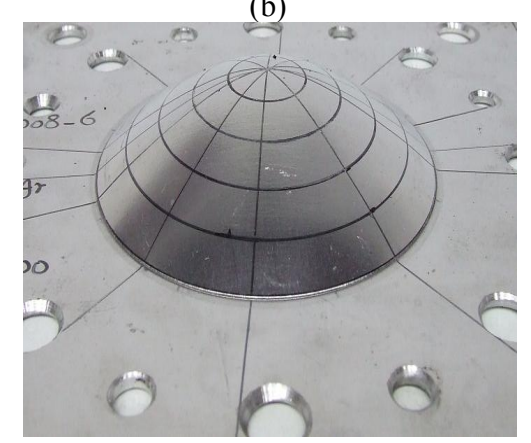

(c)

Figure 2. Photographs of typical blast loaded plates [23];(a) steel plate (thick, $3 \mathrm{~mm}$ ), (b) copper plate (thick, $3 \mathrm{~mm}$ )and(c) aluminium alloy plate (thick, $3 \mathrm{~mm}$ ) 
TABLE 2. Results of blast loading tests [23]

\begin{tabular}{|c|c|c|c|c|c|c|c|c|}
\hline Test number & $\begin{array}{c}\text { Plate } \\
\text { material }\end{array}$ & $\begin{array}{l}\text { Thickness } \\
\text { plate(mm) }\end{array}$ & $\begin{array}{l}\text { Charge } \\
\text { mass(g) }\end{array}$ & $\begin{array}{c}\text { Diameter } \\
\text { charge }(\mathrm{mm})\end{array}$ & $\begin{array}{c}\text { Stand-off } \\
\text { distance }(\mathbf{m m})\end{array}$ & Impulse(Ns) & $\begin{array}{c}\text { Mid-point } \\
\text { deflection }(\mathrm{mm})\end{array}$ & $\begin{array}{l}\text { Failure } \\
\text { mode }^{2}\end{array}$ \\
\hline HG241008-3 & steel & 1.6 & 5 & 33 & 300 & 13.02 & 11.28 & Mode I \\
\hline HG131008-4 & steel & 1.6 & 6 & 33 & 300 & 13.69 & 11.36 & Mode I \\
\hline HG131008-8 & steel & 1.6 & 8 & 33 & 300 & 17.08 & 13.72 & Mode I \\
\hline HG131008-5 & steel & 1.6 & 10 & 33 & 300 & 20.28 & 16.5 & Mode I \\
\hline HG131008-9 & steel & 1.6 & 12 & 33 & 300 & 25.07 & 20 & Mode I \\
\hline HG141008-3 & steel & 1.6 & 13 & 33 & 300 & 25.96 & 20.2 & Mode I \\
\hline HG141008-2 & steel & 1.6 & 14 & 33 & 300 & 27.5 & 22.5 & Mode I \\
\hline HG171008-4 & steel & 1.6 & 6 & 33 & 50 & 12.82 & 15.46 & Mode I \\
\hline HG171008-5 & steel & 1.6 & 10 & 33 & 50 & 19.66 & 21.6 & Mode I \\
\hline HG171008-6 & steel & 1.6 & 12 & 33 & 50 & 22.56 & --- & Mode II \\
\hline HG231008-3 & steel & 2 & 5 & 33 & 300 & 12.46 & 8.6 & Mode I \\
\hline HG131008-7 & steel & 2 & 6 & 33 & 300 & 13.6 & 9.58 & Mode I \\
\hline HG221008-3 & steel & 2 & 8 & 33 & 300 & 18.18 & 12 & Mode I \\
\hline HG131008-6 & steel & 2 & 10 & 33 & 300 & 20.55 & 13.67 & Mode I \\
\hline HG231008-8 & steel & 2 & 13 & 33 & 300 & 25.5 & 17.37 & Mode I \\
\hline HG141008-6 & steel & 2 & 13 & 33 & 300 & 26.12 & 16.7 & Mode I \\
\hline HG141008-5 & steel & 2 & 16 & 33 & 300 & 30.74 & 19.08 & Mode I \\
\hline HG141008-7 & steel & 2 & 6 & 33 & 50 & 12 & 11.73 & Mode I \\
\hline HG141008-8 & steel & 2 & 10 & 33 & 50 & 19.36 & 18.24 & Mode I \\
\hline HG141008-9 & steel & 2 & 13 & 33 & 50 & 23.78 & 21.5 & Mode I \\
\hline HG141008-10 & steel & 2 & 15 & 33 & 50 & 26.34 & --- & Mode II \\
\hline HG141008-1 & steel & 3 & 5 & 33 & 300 & 11.78 & 3.55 & Mode I \\
\hline HG131008-1 & steel & 3 & 6 & 33 & 300 & 12.75 & 3.22 & Mode I \\
\hline HG221008-11 & steel & 3 & 8 & 33 & 300 & 18.23 & 6.83 & Mode I \\
\hline HG131008-3 & steel & 3 & 10 & 33 & 300 & 20.4 & 6.66 & Mode I \\
\hline HG141008-4 & steel & 3 & 13 & 33 & 300 & 26.11 & 10.01 & Mode I \\
\hline HG231008-4 & steel & 3 & 13 & 33 & 300 & 26.5 & 10.62 & Mode I \\
\hline HG221008-12 & steel & 3 & 15 & 33 & 300 & 28.75 & 11.56 & Mode I \\
\hline HG171008-1 & steel & 3 & 6 & 33 & 50 & 11.39 & 7.28 & Mode I \\
\hline HG171008-2 & steel & 3 & 10 & 33 & 50 & 19.57 & 13.17 & Mode I \\
\hline HG221008-15 & steel & 3 & 13 & 33 & 50 & 25.09 & 14 & Mode I \\
\hline HG241008-5 & Copper & 2 & 4 & 33 & 50 & 9.35 & 9.82 & Mode I \\
\hline HG241008-6 & Copper & 2 & 7 & 33 & 50 & 15.04 & 16.11 & Mode I \\
\hline HG241008-7 & Copper & 2 & 10 & 33 & 50 & 19.22 & 22.18 & Mode I \\
\hline HG241008-11 & Copper & 2 & 13 & 33 & 50 & 24.1 & 25.97 & Mode I \\
\hline HG241008-14 & Copper & 2 & 14 & 33 & 50 & 26.4 & --- & Mode II \\
\hline HG221008-6 & Copper & 2 & 3 & 33 & 50 & 5.19 & 5.4 & Mode I \\
\hline HG221008-7 & Copper & 2 & 6 & 33 & 50 & 13.99 & 14.9 & Mode I \\
\hline HG221008-8 & Copper & 2 & 9 & 33 & 50 & 19.34 & 20 & Mode I \\
\hline HG241008-8 & Copper & 2 & 5 & 20 & 50 & 8.46 & 9.43 & Mode I \\
\hline HG241008-9 & Copper & 2 & 8 & 20 & 50 & 12.47 & 13.68 & Mode I \\
\hline HG241008-10 & Copper & 2 & 11 & 20 & 50 & 17.04 & 17.23 & Mode I \\
\hline HG241008-1 & Copper & 2 & 6 & 33 & 300 & 13.98 & 13 & Mode I \\
\hline HG241008-2 & Copper & 2 & 8 & 33 & 300 & 18.18 & 16.34 & Mode I \\
\hline HG241008-3 & Copper & 2 & 10 & 33 & 300 & 21.02 & 18.25 & Mode I \\
\hline HG221008-1 & Copper & 2 & 5 & 33 & 300 & 12.6 & 10.85 & Mode I \\
\hline HG221008-2 & Copper & 2 & 7 & 33 & 300 & 17.25 & 14.63 & Mode I \\
\hline HG221008-3 & Copper & 2 & 9 & 33 & 300 & 20.7 & 17.6 & Mode I \\
\hline HG221008-4 & Copper & 2 & 11 & 33 & 300 & 24.8 & 20.67 & Mode I \\
\hline HG221008-5 & Copper & 2 & 13 & 33 & 300 & 28.6 & --- & Mode II \\
\hline HG231008-1 & Copper & 3 & 5 & 33 & 300 & 12.39 & 7.52 & Mode I \\
\hline HG231008-2 & Copper & 3 & 9 & 33 & 300 & 19.13 & 11.85 & Mode I \\
\hline HG231008-3 & Copper & 3 & 13 & 33 & 300 & 25.61 & 15.46 & Mode I \\
\hline HG231008-5 & Copper & 3 & 16 & 33 & 300 & 30.2 & 18.12 & Mode I \\
\hline
\end{tabular}




\begin{tabular}{|c|c|c|c|c|c|c|c|c|}
\hline HG231008-6 & Copper & 3 & 19 & 33 & 300 & 34.63 & 21.2 & Mode I \\
\hline HG221008-14 & Copper & 3 & 13 & 33 & 300 & 26.46 & 15.88 & Mode I \\
\hline HG2318008-8 & Copper & 3 & 4 & 33 & 50 & 10.25 & 7.6 & Mode I \\
\hline HG231008-9 & Copper & 3 & 7 & 33 & 50 & 14.22 & 11.24 & Mode I \\
\hline HG231008-11 & Copper & 3 & 10 & 33 & 50 & 19.55 & 16.4 & Mode I \\
\hline HG231008-12 & Copper & 3 & 13 & 33 & 50 & 22.98 & 18.97 & Mode I \\
\hline HG231008-19 & Copper & 3 & 16 & 33 & 50 & 27.82 & --- & Mode II \\
\hline HG211008-7 & Aluminium & 2 & 2 & 33 & 300 & 5.16 & 8.6 & Mode I \\
\hline HG201008-5 & Aluminium & 2 & 3 & 33 & 300 & 8.25 & 14.9 & Mode I \\
\hline HG201008-7 & Aluminium & 2 & 4 & 33 & 300 & 10.82 & 24.22 & Mode I \\
\hline HG211008-8 & Aluminium & 2 & 4.5 & 33 & 300 & 12.32 & 26.3 & Mode I \\
\hline HG231008-7 & Aluminium & 2 & 3.5 & 33 & 300 & 9 & 21 & Mode I \\
\hline HG211008-9 & Aluminium & 2 & 5 & 33 & 300 & 14.1 & --- & Mode II \\
\hline HG201008-8 & Aluminium & 2 & 2 & 33 & 50 & 2.72 & 7.35 & Mode I \\
\hline HG211008-1 & Aluminium & 2 & 3 & 33 & 50 & 3.91 & 11.4 & Mode I \\
\hline HG211008-2 & Aluminium & 2 & 4 & 33 & 50 & 8.62 & 23.3 & Mode I \\
\hline HG241008-13 & Aluminium & 2 & 2.5 & 20 & 50 & 4.92 & 15.24 & Mode I \\
\hline HG241008-12 & Aluminium & 2 & 3.5 & 20 & 50 & 7.44 & 19.04 & Mode I \\
\hline HG211008-10 & Aluminium & 2 & 4.5 & 33 & 50 & 9.75 & --- & Mode II \\
\hline HG201008-1 & Aluminium & 3 & 4 & 33 & 300 & 9.72 & 14.1 & Mode I \\
\hline HG211008-6 & Aluminium & 3 & 5 & 33 & 300 & 13.71 & 19.9 & Mode I \\
\hline HG201008-2 & Aluminium & 3 & 6 & 33 & 300 & 14.96 & 21.9 & Mode I \\
\hline HG201008-9 & Aluminium & 3 & 7 & 33 & 300 & 16.2 & --- & Mode II \\
\hline HG211008-5 & Aluminium & 3 & 3 & 33 & 50 & 2.72 & 5.4 & Mode I \\
\hline HG211008-4 & Aluminium & 3 & 4 & 33 & 50 & 10.84 & 15.97 & Mode I \\
\hline HG211008-3 & Aluminium & 3 & 5 & 33 & 50 & 11.54 & 22.9 & Mode I \\
\hline HG231008-10 & Aluminium & 3 & 4.5 & 33 & 50 & 9.65 & 17.21 & Mode I \\
\hline HG231008-14 & Aluminium & 3 & 4 & 20 & 50 & 7.28 & 14.56 & Mode I \\
\hline HG231008-15 & Aluminium & 3 & 5 & 20 & 50 & 9.28 & 16.88 & Mode I \\
\hline HG231008-16 & Aluminium & 3 & 6 & 20 & 50 & 10.2 & 21 & Mode I \\
\hline HG231008-17 & Aluminium & 3 & 7 & 20 & 50 & 11.91 & 21.6 & Mode I \\
\hline HG211008-11 & Aluminium & 3 & 6 & 33 & 50 & 12.8 & --- & Mode II \\
\hline
\end{tabular}

General connection between inputs and output variables can be expressed by a complicated polynomial of the form:

$$
y=a_{0}+\sum_{i=1}^{n} a_{i} x_{i}+\sum_{i=1}^{n} \sum_{j=1}^{n} a_{i j} x_{i} x_{j}+\sum_{i=1}^{n} \sum_{j=1}^{n} \sum_{k=1}^{n} a_{i j k} x_{i} x_{j} x_{k}+\ldots
$$

which is known as the Ivakhnenko polynomial [24]. However, for most applications the quadratic form of only two variables is used in the form:

$$
\hat{y}=G\left(x_{i}, x_{j}\right)=a_{0}+a_{1} x_{i}+a_{2} x_{j}+a_{3} x_{i} x_{j}+a_{4} x_{i}^{2}+a_{5} x_{j}^{2}
$$

to predict the output $y$. The coefficient $a_{i}$ in Equation (5) is calculated using regression techniques [25-27] so that the difference between actual output, $y$, and the calculated one, $\hat{y}$, for each pair of $x_{i}, x_{j}$ as input variables is minimized. Indeed, it can be seen that a tree of polynomials is constructed using the quadratic form given in Equation (5) whose coefficients are obtained in a least-squares sense. In this way, the coefficients of each quadratic function $G_{i}$ are obtained to optimally fit the output in the whole set of inputoutput data pair, that is:

$$
r^{2}=\frac{\sum_{i=1}^{M}\left(y_{i}-G_{i}(0)^{2}\right.}{\sum_{i=1}^{M} y_{i}^{2}} \rightarrow \min
$$

In the basic form of the GMDH algorithm, all the possibilities of two independent variables out of total $n$ input variables are taken in order to construct the regression polynomial in the form of Equation (5) that best fits the dependent observations $\left(y_{i}, i=1,2, \ldots\right.$, $M)$ in a least-squares sense. Consequently, $\left(\begin{array}{l}n \\ 2\end{array}\right)=\frac{n(n-1)}{2}$ neurons will be built up in the second layer of the feed forward network from the observations $\left\{\left(y_{i}, x_{i p}, x_{i q}\right)\right.$; $(i=1,2, \ldots, M)\}$ for different $p, q \in\{1,2, \ldots, M\}$ [28]. In other words, it is now possible to construct $\mathrm{M}$ data triples $\left\{\left(y_{i}, x_{i p}, x_{i q}\right) ;(i=1,2, \ldots, M)\right\}$ from observation using such $p, q \in\{1,2, \ldots, M\}$ in the form:

$$
\left[\begin{array}{cc:c}
X_{1 p} & X_{1 q} & y_{1} \\
X_{2 p} & X_{2 q} & y_{2} \\
\hdashline X_{M p} & X_{M q} & Y_{M}
\end{array}\right]
$$


Using the quadratic sub-expression in the form of Equation (5) for each row of $M$ data triples, the following matrix equation can be readily obtained as:

$$
A \mathbf{a}=\mathbf{Y}
$$

where $\mathbf{a}$ is the vector of unknown coefficients of the quadratic polynomial in Equation (5):

$$
\mathbf{a}=\left\{a_{0}, a_{1}, a_{2}, a_{3}, a_{4}, a_{5}\right\}
$$

and

$$
\mathbf{Y}=\left\{y_{1}, y_{2}, y_{3}, \ldots, y_{M}\right\}^{T}
$$

is the vector of output value from observation. It can be readily seen that

$$
A=\left[\begin{array}{cccccc}
1 & X_{1 p} & X_{1 q} & X_{1 p} X_{1 q} & X_{1 p}^{2} & X_{1 q}^{2} \\
1 & X_{2} p & X_{2} q & X_{2} X_{2 q} & X_{2}^{2} p & X_{2}^{2} \\
\hdashline 1 & X_{M p} & X_{M q} & X_{M p} X_{M q} & X_{M p}^{2} & X_{M q}^{2}
\end{array}\right]
$$

The least-squares technique from multiple-regression analysis leads to the solution of the normal equations in the form of:

$$
\mathbf{a}=\left(A^{T} A\right)^{-1} A^{T} \mathbf{Y}
$$

which determines the vector of the best coefficients of the quadratic Equation (5) for the whole set of $M$ data triples. However, such solution directly from normal equations is rather susceptible to round off error and, more importantly, to the singularity of these equations. SVD is the method for solving most linear least squares problems where some singularities may exist in the normal equations. The SVD of a matrix, $A \in \mathfrak{R}^{M \times 6}$, is a factorisation of the matrix into the product of three matrices, column-orthogonal matrix $U \in \mathfrak{R}^{M \times 6}$, diagonal matrix $W \in \mathfrak{R}^{6 \times 6}$ with nonnegative elements (singular values), and orthogonal matrix $V \in \mathfrak{R}^{6 \times 6}$ such that

$$
A=U W V^{T}
$$

The most popular technique for computing the SVD was originally proposed by Taylor [29]. The problem of optimal selection of vector of the coefficients in Equations (8) and (11) is firstly reduced to find the modified inversion of diagonal matrix $W$ (Press et al. [27]) in which the reciprocals of zero or near zero singulars (according to a threshold) are set to zero. Then, such optimal $\mathbf{a}$ is calculated using the following relation $[24,27]$ :

$$
\mathbf{a}=V\left[\operatorname{diag}\left(1 / w_{j}\right) U^{T} \mathbf{Y}\right.
$$

Such procedure of SVD approach of finding the optimal coefficients of quadratic polynomials, $\mathbf{a}$, improves the performance of self-organizing GMDH type algorithms that is employed to build networks based on input-output observation data triples.

\section{STRUCTURE IDENTIFICATION OF GMDH-TYPE NETWORKS}

For simultaneous determination of structure and parametric identification of GMDH-type neural networks, the numbers of layers as well as the number of neurons in each layer are determined according to a threshold for error Equation (6). In addition, unlike two previous approaches, some of input variables or generated neurons in different layers can be included in subsequent layers. The main steps of this approach are described as follows [24]:

Step 1: Set K=1; Set Threshold.

Step 2: Construct $N_{K}^{\prime}=\frac{N_{K}\left(N_{K}-1\right)}{2}$ neurons according to all possibilities of connection by each pair of neurons in the layer. This can be achieved by forming the quadratic expression $G\left(x_{i}, x_{j}\right)$ which approximates the output $y$ in Equation (5) with least-squares errors of Equation (6) either by solving the normal Equation (11) or by SVD approach Equation (13).

Step 3: Select the single best neuron out of these $N_{k}^{\prime}$ neurons, $x^{\prime}$, according to its value of $r^{2}$. If (Error $<$ Threshold) Then END; Otherwise Set Vec_of Var $=\{$ $\left.x_{1}, x_{2}, x_{3}, \ldots, x_{n}, x^{\prime}\right\}$.

Step4: Set $N_{k}=N_{k}+1$; goto 2 .

\section{GMDH-TYPE NEURAL NETWORK MODELLING AND PREDICTION OF DEFORMATION OF CIRCULAR PLATES SUBJECTED TO IMPULSIVE LOADING}

The method described in previous sections is now used to design GMDH-type network systems for a set of dimensionless parameters constructed upon experimental input-output data in a series of explosive forming tests given in Table 2. Accordingly, the set of output-inputs variables used to train the GMDH-type neural network is a dimensionless set, $\Pi=$ $\left\{\pi_{1}, \pi_{2}, \pi_{3}, \pi_{4}, \ldots, \pi_{k}\right\}$, rather than the set of real physical variables $\{\mathrm{y}, \mathrm{X}\}=\left\{\mathrm{y}, \mathrm{x}_{1}, \mathrm{x}_{2}, \mathrm{x}_{3}, \ldots, \mathrm{x}_{\mathrm{n}}\right\}$. Hence, given $M$ observation of multi-input-single-output data pairs which have been converted to the equivalent dimensionless parameters [27] so that:

$\pi_{1 i}=f\left(\pi_{2 i}, \pi_{3 i}, \pi_{4 i}, \ldots, \pi_{k i}\right)(i=1,2, \ldots, M)$, 
it is now possible to train a GMDH-type neural network to predict the output values $\hat{\pi}_{1 i}$ for any given input vector $\left(\pi_{2 i}, \pi_{3 i}, \pi_{4 i}, \ldots, \pi_{k i}\right)$, that is:

$$
\hat{\pi}_{1 i}=\hat{f}\left(\pi_{2 i}, \pi_{3 i}, \pi_{4 i}, \ldots, \pi_{k i}\right)(i=1,2, \ldots, M)
$$

The problem is now to determine a GMDH-type neural network so that the square of difference between the actual dimensionless output and the predicted one is minimised, that is:

$$
\sum_{i=1}^{M}\left[\hat{f}\left(\pi_{2 i}, \pi_{3 i}, \pi_{4 i}, \ldots, \pi_{k i}\right)-\hat{\pi}_{1 i}\right]^{2} \rightarrow \text { min }
$$

Again, the quadratic form of only two variables is used in the form [28]:

$$
\begin{gathered}
\hat{\pi}_{1}=G\left(\pi_{i}, \pi_{j}\right)=a_{0}+a_{1} \pi_{i}+a_{2} \pi_{j}+ \\
a_{3} \pi_{i} \pi_{j}+a_{4} \pi_{i}^{2}+a_{5} \pi_{j}^{2}
\end{gathered}
$$

to predict the output $\pi_{1}$.

In order to construct such independent dimensionless parameters in the case of modelling of mid-point deflection $\mathrm{W}_{\circ}(\mathrm{mm})$, total impulse I(N.s), plate thickness $H(\mathrm{~mm})$, plate radius $R_{p}(\mathrm{~mm})$, charge radius $R_{c}(\mathrm{~mm})$, stand-off distance $\mathrm{S}(\mathrm{mm})$, density $\rho$ $\left(\mathrm{kg} / \mathrm{m}^{3}\right)$ and static yield stress $\sigma_{o}(\mathrm{MPa})$ have been considered as input parameters in neural network, that is:

$\mathrm{W}_{\mathrm{o}}=\mathrm{f}\left(\mathrm{I}, \mathrm{H}, \mathrm{R}_{\mathrm{p}}, \mathrm{R}_{\mathrm{c}}, \mathrm{S}, \rho, \sigma_{o}\right)$.

From this set of inputs-output parameters, 4 independent dimensionless parameters have been constructed [26] according to 3 main dimensions (M, $\mathrm{L}, \mathrm{T})$, as follows:

$$
\begin{aligned}
& \pi_{1}=\frac{W_{o}}{H} \\
& \pi_{2}=\sqrt{\frac{\rho V_{o}^{2}}{\sigma_{o}}}=\frac{I}{\pi H R_{p}^{2} \sqrt{\rho \sigma_{o}}} \\
& \pi_{3}=\frac{S}{R_{p}} \\
& \pi_{4}=\frac{R_{C}}{H},
\end{aligned}
$$

It should be noted that in Equation (19-b) $V_{o}=\frac{I}{M_{p}}$ and $M_{p}=\rho\left(\mathrm{Vol}_{\text {plate }}\right)$ are the impact velocity and the mass of the plate, respectively, so that:

$$
\pi_{1}=f\left(\pi_{2}, \pi_{3}, \pi_{3}\right)
$$

It should be noted that the simplest possible dimensionless parameters have been considered according to the involved physical parameters.
The model is based on experimental data presented in Table 2; the multi-input-single-output set of constructed dimensionless data according to Equations $(19-a)$ to $(19-d)$ were developed. The method previously mentioned was used separately in conjunction with either normal equations approach or SVD approach for the coefficient of the quadratic polynomials. The result shows that SVD approach for finding the quadratic polynomial coefficients is either superior or very close to direct solving of normal equations. Table 3 demonstrates such comparison of modelling errors (which have been calculated by Equation (6)) using normal equations and SVD. Accordingly, Figure 3 shows the behaviour of the midpoint deflection thickness ratio, using GMDH-type network model constructed with singular value decomposition approach for the coefficients of the quadratic polynomials. It is evident from Figure 3 that the confidence envelope for obtained model is reported as $85 \%$ for \pm 1 displacement-thickness ratio. The structures of GMDH-type network are depicted in Figure 4. Consequently, it is now possible to present the obtained polynomial equations for mid-point deflection thickness ratio based on the structure of the GMDH-type neural network depicted in Figure 4 using SVD approach for the coefficient of the quadratic polynomials in the form of

$\mathrm{H}=-0.1362+0.5843 \pi_{1}-0.1201 \pi_{2}-0.004156 \pi_{1}^{2}-$

$0.02341 \pi_{2}^{2}-0.008238 \pi_{1} \pi_{2}$,

$\pi_{1}=-1.608+0.5760 \pi_{2}+0.9266 \mathrm{H}-0.05507 \pi_{2}^{2}-$ $0.009021 \mathrm{H}^{2}+0.02914 \pi_{2} \mathrm{H}$

In order to demonstrate the prediction ability of such GMDH-type neural networks in the case of dimensionless modelling, the data have been randomly divided into two different sets, namely, training and testing sets. The training set, which consists of 38 out of 77 inputs-output data pairs, is used for training the GMDH-type neural network models using either solving normal equations approach or SVD approach for the coefficients of the quadratic polynomials. The testing set, which consists of 39 unforeseen inputsoutput data samples during the training process, is merely used for testing to show the prediction ability of such GMDH-type neural network models during the training process.

In this way, Table 4 demonstrates such comparison of modelling and prediction errors (which have been calculated by Equation (6))using normal equations and SVD. Accordingly, Figure 5 shows the modelling and prediction mid-point deflection thickness ratio, using GMDH-type network model constructed with singular value decomposition approach for the coefficients of the quadratic polynomials. It is evident from Figure 5 that the confidence envelope for obtained model is reported as $89 \%$ for \pm 1 displacement-thickness ratio. 


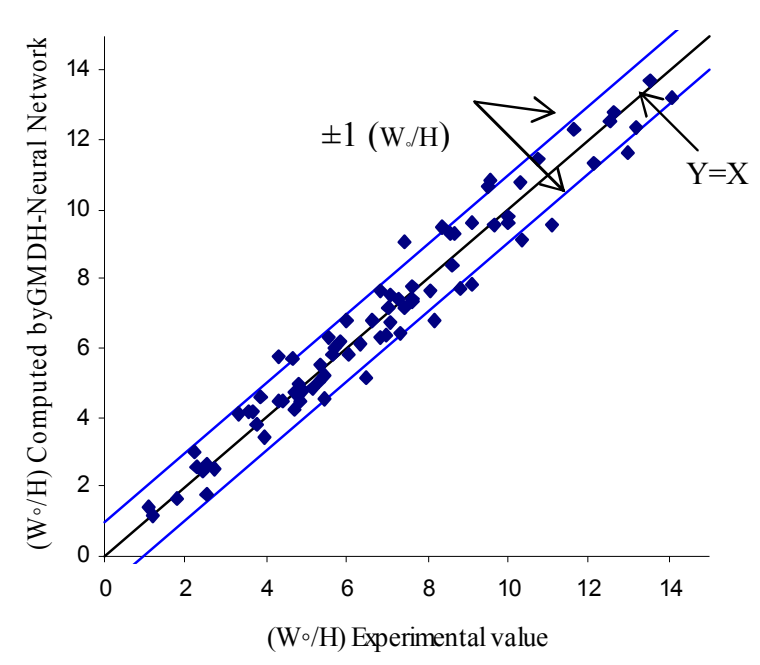

Figure 3. Comparison of experimental values with computed values by GMDH-type network

TABLE 3. Values of modeling error

\begin{tabular}{lcc}
\hline Method & $\begin{array}{c}\text { Using normal equations } \\
\text { approach }\end{array}$ & $\begin{array}{c}\text { Using } \\
\text { SVDapproach }\end{array}$ \\
\hline Error & 0.009132 & 0.007979 \\
\hline
\end{tabular}

TABLE 4. values of modelling and prediction error

\begin{tabular}{lcc}
\hline Method & $\begin{array}{c}\text { Using normal equations } \\
\text { approach }\end{array}$ & $\begin{array}{c}\text { Using } \\
\text { SVDapproach }\end{array}$ \\
\hline Error & 0.00956 & 0.00832 \\
\hline
\end{tabular}

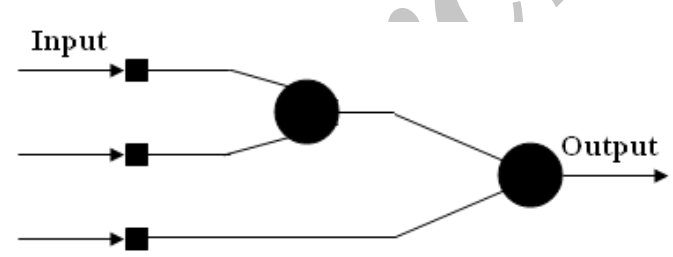

Figure 4. GMDH-type network for mid-point deflection thickness ratio

\section{CONCLUSION}

The experimental results in this paper represent the behaviour of ferrous and non-ferrous plates subjected to impulse loading. The results can provide a model between mil-point deflections and applied impulsive load. A method for designing GMDH-type networks has been proposed and successfully used for the modelling and prediction of the process parameters of very complex process of deformation of circular plates subjected to impulsive loading. In this way, it has been shown that GMDH-type networks provide effective means to model and predict mid-point deflection thickness ratio according to different inputs. Moreover, it has been shown that singular value decomposition can effectively improve the performance of such GMDH-type networks over the traditional use of normal equations when all inputs-output data pairs are used for the modelling.

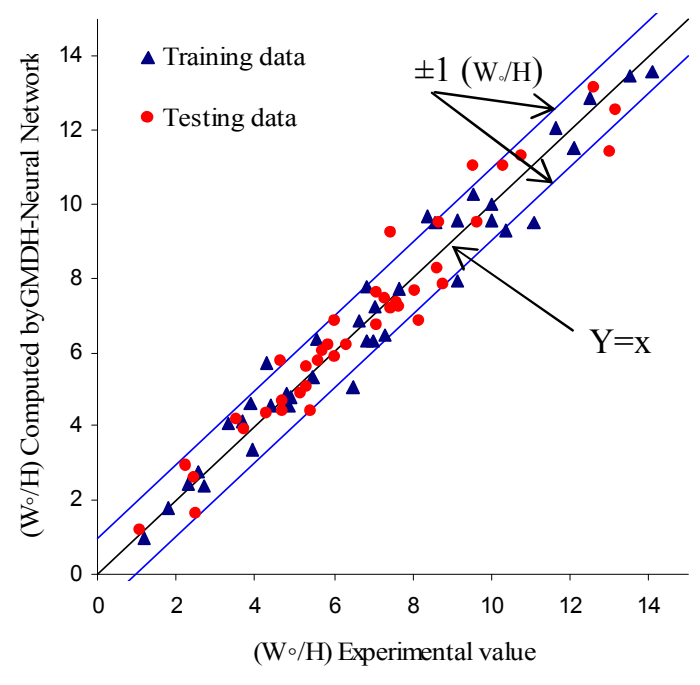

Figure 5. Comparison of experimental values with computed/predicted values by GMDH-type network

\section{REFERENCES}

1. Kim, T., Kim, H., Bae, J., Lee, S. and Kang, C., "Semi-solid die forging of al6061 wrought aluminium alloy with electromagnetic stirring", Proceedings of the Institution of Mechanical Engineers, Part B: Journal of Engineering Manufacture, Vol. 222, No. 9, (2008), 1083-1095.

2. Gerdooei, M. and Dariani, B., "Strain-rate-dependent forming limit diagrams for sheet metals", Proceedings of the Institution of Mechanical Engineers, Part B: Journal of Engineering Manufacture, Vol. 222, No. 12, (2008), 1651-1659.

3. Tavakoli, H. and Kiakojouri, F., "Influence of sudden column loss on dynamic response of steel moment frames under blast loading", International Journal of Engineering-Transactions B: Applications, Vol. 26, No. 2, (2012), 197-206.

4. Nurick, G. and Martin, J., "Deformation of thin plates subjected to impulsive loading - a review: Part i: Theoretical considerations", International Journal of Impact Engineering, Vol. 8, No. 2, (1989), 159-170.

5. Nurick, G. and Martin, J., "Deformation of thin plates subjected to impulsive loading - a review part ii: Experimental studies", International Journal of Impact Engineering, Vol. 8, No. 2, (1989), 171-186. 
6. Teeling-Smith, R. and Nurick, G., "The deformation and tearing of thin circular plates subjected to impulsive loads", International Journal of Impact Engineering, Vol. 11, No. 1, (1991), 77-91.

7. Kowsarnia, E., Alizadeh, Y. and Salavati Pour, H.S., "Experimental evaluation of blast wave parameters in under water explosion of hexogen charges", International Journal of Engineering-Transactions B: Applications, Vol. 25, No. 1, (2012), 65-72

8. Mynors, D.J. and Zhang, B., "Applications and capabilities of explosive forming", Journal of materials processing technology, Vol. 125, (2002), 1-25.

9. Johnson, W., "Liberator on explosive forming", CMEChartered Mech. Eng., Vol. 34, No. 12, (2011).

10. Jones, N., "Impulsive loading of a simply supported circular rigid plastic plate", Journal of Applied Mechanics, Vol. 35, No. 1, (1968), 59-65.

11. Åström, K.J. and Eykhoff, P., "System identification-a survey", Automatica, Vol. 7, No. 2, (1971), 123-162.

12. Sanchez, E., Zadeh, L.A. and Shibata, T., "Genetic algorithms and fuzzy logic systems, World Scientific, (1997).

13. Austina, N., Kumarb, P.S. and Kanthavelkumaranc, N., "Artificial neural network involved in the action of optimum mixed refrigerant (domestic refrigerator)", International Journal of Engineering, Vol. 26, No. 10, (2013).,1025-2495

14. Nariman-Zadeh, N. and Darvizeh, A., "Design of fuzzy systems for modelling of explosive cutting process of plates using singular value decomposition", Iranian Journal of Science and Technology, Vol. 26, No. B3, (2002), 455-464.

15. Kristinsson, K. and Dumont, G.A., "System identification and control using genetic algorithms", Systems, Man and Cybernetics, IEEE Transactions on, Vol. 22, No. 5, (1992), 1033-1046.

16. Bagheri, A., Narimanzadeh , N., Siavash, A.S. and Khoobkar, A.R., "Gmdh type neural networks and their application to the identification of the inverse kinematics equations of robotic manipulators (research note)", International Journal of Engineering, Vol. 18, No. 2, (2005), 135-143

17. Iba, H. and Sato, T., "A numerical approach tô genetic programming for system identification", Evolutionary Computation, Vol. 3, No. 4, (1995), 417-452.

18. Porter, B. and Nariman-Zadeh, N., "Genetic design of computed-torque fuzzy logic controllers for robotic manipulators", in Proc. IEEE Int. Symp. On Int. Control, USA. (1995).

19. Ivakhnenko, A., "Polynomial theory of complex systems", Systems, Man and Cybernetics, IEEE Transactions on, No. 4, (1971), 364-378

20. Farlow, S.J., "Self-organizing methods in modeling: Gmdh type algorithms, CrC Press, Vol. 54, (1984).

21. Back, T., Fogel, D.B. and Michalewicz, Z., "Handbook of evolutionary computation, IOP Publishing Ltd., (1997).

22. Darvizeh, A., Nariman-Zadeh, N. and Gharababaei, H., "Gmdh-type neural network modelling of explosive cutting process of plates using singular value decomposition", Systems Analysis Modelling Simulation, Vol. 43, No. 10, (2003), 1383-1397.

23. Gharababaei, H. and Darvizeh, A., "Experimental and analytical investigation of large deformation of thin circular plates subjected to localized and uniform impulsive loading", Mechanics Based Design of Structures and Machines, Vol. 38, No. 2, (2010), 171-189.

24. Golub, G.H. and Reinsch, C., "Singular value decomposition and least squares solutions", Numerische Mathematik, Vol. 14, No. 5, (1970), 403-420.

25. Mahmoodabadi, M., Taherkhorsandi, M. and Safikhani, H., "Modeling and hybrid pareto optimization of cyclone separators using group method of data handling (GMDH) and particle swarm optimization (pso)", International Journal of Engineering-Transactions C: Aspects, Vol. 26, No. 9, (2012), 1089.

26. Nariman-Zadeh, N., Darvizeh, A., Felezi, M. and Gharababaei, H., "Polynomial modelling of explosive compaction process of metallic powders using gmdh-type neural networks and singular value decomposition", Modelling and Simulation in Materials Science and Engineering, Vol. 10, No. 6, (2002), 727.

27. Press, W., Teukolsky, S., Vetterling, W. and Flannery, B. Numerical recipes in fortran 77: The art of scientific computing, , Cambridge Univ. Press, New York.(1992)

28. Gharababaei, H., Nariman-Zadeh, N. and Darvizeh, A., "A simple modelling method for deflection of circular plates under impulsive loading using dimensionless analysis and singular value decomposition", Journal of Mechanics, Vol. 26, No. 03, (2010), 355-361.

29. Taylor, E.S., "Dimensional analysis for engineers",

(1974) 


\title{
Prediction of Deformation of Circular Plates Subjected to Impulsive Loading Using GMDH-type Neural Network
}

\author{
H. Babaei
}

Department of Mechanical Engineering, Engineering Faculty, University of Guilan, Rasht, Iran

PAPER INFO

Paper history:

Received 11 August 2013

Received in revised form 31 May 2014

Accepted 26 June 2014

\section{Keywords:}

Neural Network

Modelling, Circular Plate

Impulsive Load

Deformation
در اين مقاله ياسخ ورقهاى كيردار دايروى از جنس فولاد نرم، مس و آلومينيوم تحت بار انفجارى بصورت تجربى بررسى

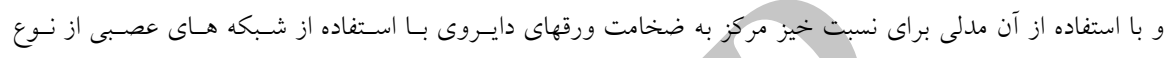
GMDH

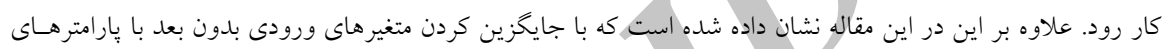

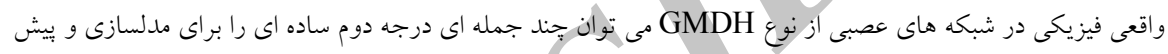

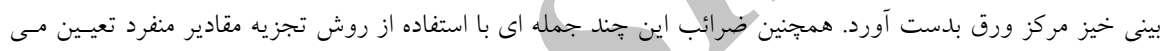

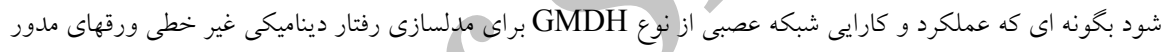
بهبود مى يابد. 


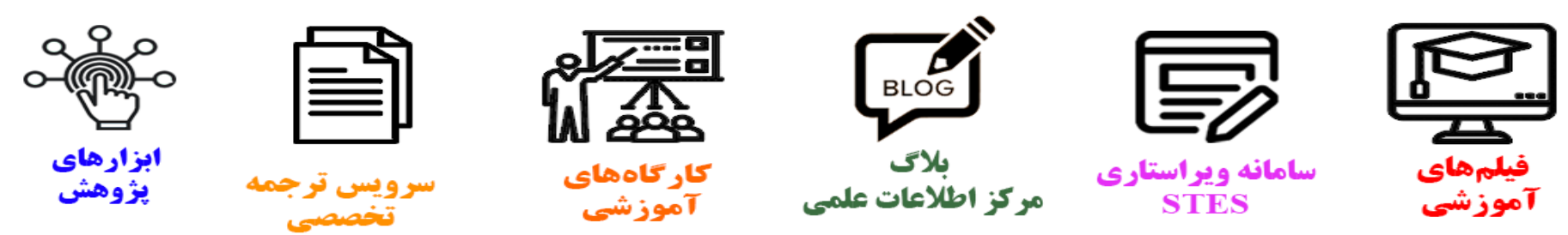

\section{(c)}

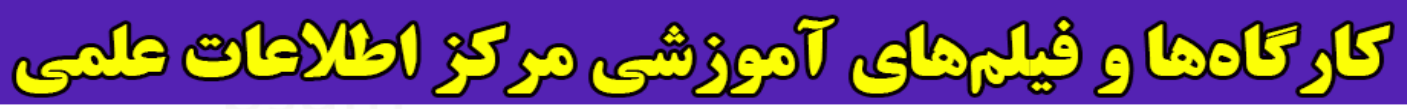
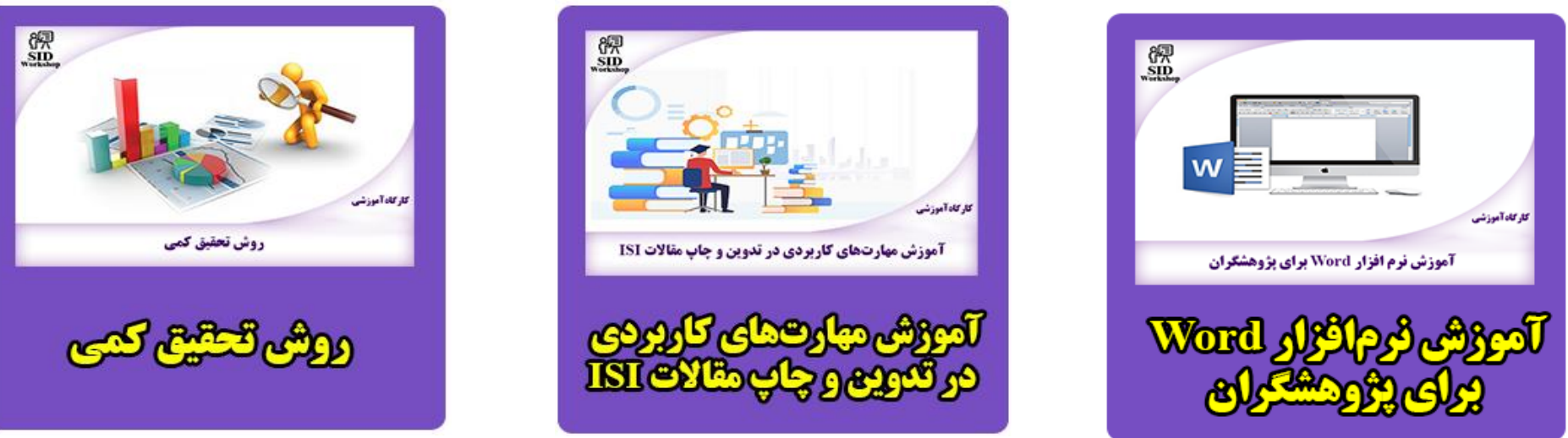